\title{
ASG-EUPOS MONITORING WITH REFERENCE TO EPN
}

\author{
Mariusz Figurski, \\ Paweł Kamiński \\ Krzysztof Kroszczyński \\ Karolina Szafranek \\ Centre of Applied Geomatics \\ Military University of Technology, Warsaw \\ Kaliskiego Street 2 \\ 00-908 Warsaw, Poland \\ e-mails: mfigurski@wat.edu.pl, kszafranek@wat.edu.pl
}

\begin{abstract}
This paper concerns methods and results of processing of data collected by ASG-EUPOS (Active Geodetic Network - European Position Determination System) sites since the beginning of the system. The elaboration was made by Centre of Applied Geomatics from Military University of Technology and it was based on the experience gained during EPN (European Permanent Network) processing. Strategy was similar to strategy used by EPN Local Analysis Centers for European network elaborations and EPN test reprocessing (Kenyeres et al., 2008). As the outcome daily and weekly solutions (North, East, Up component for each station) were obtained. Basing on weekly solutions local velocities and vertical movements were determined. Preliminary tests of combining national and regional networks were also made and results were compared to official EPN solutions (differences below $1 \mathrm{~cm}$ ). Daily solutions were analyzed in the context of stability and reliability basing on time series standard deviation.
\end{abstract}

Keywords: ASG-EUPOS, EPN, GNSS processing

\section{INTRODUCTION}

ASG-EUPOS is Polish GNSS Ground Based Augmentation System. The name ASG-EUPOS stands for Active Geodetic Network European Position Determination System. ASG-EUPOS consists of more than 100 GNSS reference stations, which constitute densification of global (International GNSS System - IGS) and regional (EUREF Permanent Network - EPN) GNSS networks. Data collected by those stations is a reference for many surveys (real time or postprocessing corrections - differential technology). ASG-EUPOS will take role of main national geodetic frame and will enable conservation of ETRF (European Terrestrial Reference Frame) in Poland. That is one of the reasons why system activity has to be monitored and controlled. The system is managed by Polish Head Office of Geodesy and Cartography (HOGC).

Due to agreement with HOGC, Centre of Applied Geomatics from Military University of Technology (CAG MUT) has an access to all data gathered since the beginning of the system's activity. CAG processes the data, checks their correctness and analyses solutions. This paper concerns daily solutions (North, East, Up component for each station) obtained from processing made for the data from all available Polish stations, for foreign, border stations and for some EPN stations. 
Strategy of processing was based on strategy used by EPN Local Analysis Centers for European network elaborations (Kenyeres et al., 2008). The calculations were made from November 2006 to February 2009, although most Polish stations started to gather data at the end of 2007. Obtained solutions were analyzed in the context of stability and reliability and they were compared to official EPN solutions. Preliminary tests of combining national and regional networks were also made.

As a reference (datum definition) a few EPN stations were used (BOR1, WTZR, METS, POTS, ONSA). The calculations were made from November 2006 to February 2009, although most Polish stations started to gather data at the end of 2007.

\section{STRATEGY OF ASG-EUPOS PROCESSING}

Processing was made using Bernese 5.0 software (Beutler et al., 2006). Strategy of processing was very similar to EPN test reprocessing strategy (Kenyeres et al., 2008). Only GPS observations in RINEX format were used with carrier phase as a basic observable. Elevation angle cutoff was 3 degrees and elevation dependent weighting was done using $\cos (\mathrm{z})$. As modeled observable double-differences (ionosphere-free linear combination) were used. Table 1 presents basic elements of strategy. Models used during processing are gathered in Table 2. The detailed description of preparation for ASG-EUPOS elaboration and polish GNSS stations processing strategy was shown in (Figurski, 2007).

Table 1. Processing strategy

\section{Processing strategy}

Modeled observable: double-differences, ionosphere-free linear combination;

Ground and Satellite antenna phase center calibrations: absolute model (if available);

Troposphere: During the processing Saastamoinen-based dry component mapped with the Dry-Niell mapping function was used as a priori model. The Wet-Niell mapping function was employed to map the wet component (without a priori model). Estimation of zenith delay corrections was made at 1-hour intervals for each station. Horizontal gradient parameter was estimated for each station per day (TILTING) with no a priori constraints. Daily TRO files (files containing troposphere data - processing outcome) with cumulative coordinates input were computed from weekly solution;

Ionosphere: For the final adjustment, ionosphere was cancelled out due to ionosphere - free linear combination used, but CODE (The Center for Orbit Determination in Europe) global iono models helped to increase the number of resolved ambiguities in the QIF, the L5/L3 and the L1/L2 ambiguity resolution;

Satellite clock corrections: Not estimated, but biases eliminated by forming double differences;

Receiver clock corrections: Estimated as part of the biases preprocessing using code measurements, finally eliminated by forming double differences;

Orbits and ERPs: IGS precise final orbits and ERPs;

Ambiguity: Method of ambiguity determination depended on the length of a baseline. For baselines up to $1300 \mathrm{~km}$ length QIF strategy in a baseline processing mode using CODE global iono models was used. For baseline lengths shorter than $200 \mathrm{~km}$ L5/L3 approach was employed and for baselines shorter than $20 \mathrm{~km}-\mathrm{L1} / \mathrm{L} 2$ approach. 
Table 2. Models used in processing

Planetary ephemeris: DE405

Ocean tides: OT_CSRC

The Earth geopotential is modeled using: JGM3

Nutation model: IAU2000

Subdaily pole model: IERS2000

Tidal displacements:

Solid tides: according to the IERS 1996/2000 standards

Ocean loading model: FES2004

Weekly and daily solutions were obtained in SINEX format. As the processing solutions were expressed in ITRF, the transformation according to 7th version of (Altamimi et al., 2008) was done to obtain coordinates in ETRF.

\section{PROCESSING SOLUTIONS}

As an outcome of processing weekly and daily solutions were obtained. Weekly solutions are used for ETRS realization and to determine local velocities (Dense European Velocity Field Programme - Altamimi, 2004). They were processed and analyzed similarly to EPN, as a result they can be joined and compared. Figure 1 shows horizontal velocities determined within Poland using weekly solutions expressed in ETRF. Time series that were used are too short to obtain reliable velocity solutions, so this is only an introduction to further investigations.

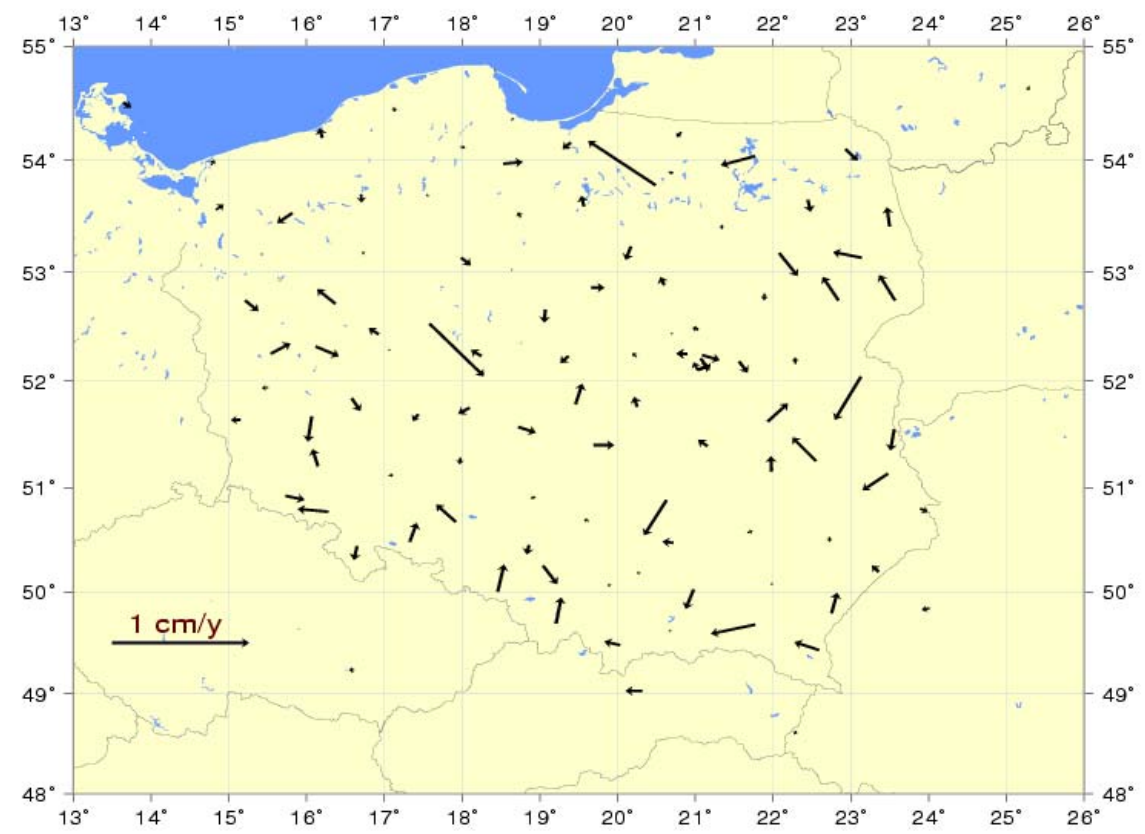

Fig. 1. Horizontal velocities in ETRF (based on weekly solutions)

Daily solutions are a densification of weekly solutions. Changes on stations were not taken into consideration, that is why there are some discontinuities in time series. The main role of daily solutions is to realize ETRS in Poland and to check proper station operation.

The EPN stations are categorized to provide the most reliable products. This classification takes into account solutions' quality and the length of available observation period. Regular official updates of the ITRS/ETRS89 coordinates/velocities of the EPN stations are released every 15 weeks. After every update, sites are divided into two classes (Kenyeres, 2009). The criteria are related to the length of observation period, the precision of position and the agreement (in terms of repeatability) between the velocity estimations from the last 10 consecutive cumulative solutions. Determination of stable and reliable velocities from 
cumulative solutions requires at least few years of observations. Polish stations' time series are very short (8-21 months), so there cannot be reliable velocity estimation - different criteria of solutions quality estimation had to be used. Criteria employed for analyzed sites classification are independent of EPN service, this is due to different character of data (length of observation period) and purposes. The main aim of EPN stations classifications is to determine which of them can be used as a reference for national densifications (tough criterion concerning stability of velocities), whereas this case the main purpose is stations' proper activity estimation. The authors propose the same criteria for both ASG-EUPOS and added EPN sites, because quality of their solutions is comparable, although the national network is the densification of the European network (five reference stations: BOR1, WTZR, METS, POTS, ONSA with minimum constraints approach).

Accuracy of coordinates determined using GNSS methods tells how much do the solutions differ from the 'real' value (which is not known, unless catalogue value is assumed). To estimate the coordinates accuracy two approaches can be used. First method is based on P repeatability of solutions obtained during consecutive sessions (daily solutions), which can be calculated using the formula:

$$
P=\sqrt{\frac{\frac{n}{n}-1 \sum_{i=1}^{n} \frac{(R i-R m)^{2}}{\sigma_{i}^{2}}}{\sum_{i=1}^{n} \frac{1}{\sigma_{i}^{2}}}}
$$

in which $\mathrm{n}$ is number of sessions (daily solutions), $\mathrm{R}_{\mathrm{i}}$ means coordinates obtained during processing, $R_{m}$ - the mean value of coordinates from all sessions and $\sigma_{i}$ - root mean square error determined during elaboration. Second method consists of standard deviation usage.

To investigate accuracy and correctness of ASG-EUPOS solutions second method was employed (similar errors for all determined solution) - standard deviation for time series of each station was calculated separately for North-East and Up components. Basing on these values, all stations were divided into classes. The criteria are given in Table 2. Figures 2-7 present stations divided into classes basing on horizontal and vertical standard deviation and examples of time series from selected sites.

Table 2. The criteria of sites' division into classes.

\begin{tabular}{|c|c|c|}
\hline & North-East [mm] & Up [mm] \\
\hline I & $1.00<\sigma<1.40$ & $2.50<\sigma<3.50$ \\
\hline II & $1.40<\sigma<1.70$ & $3.50<\sigma<4.00$ \\
\hline III & $1.70<\sigma<3.00$ & $4.00<\sigma<5.00$ \\
\hline
\end{tabular}




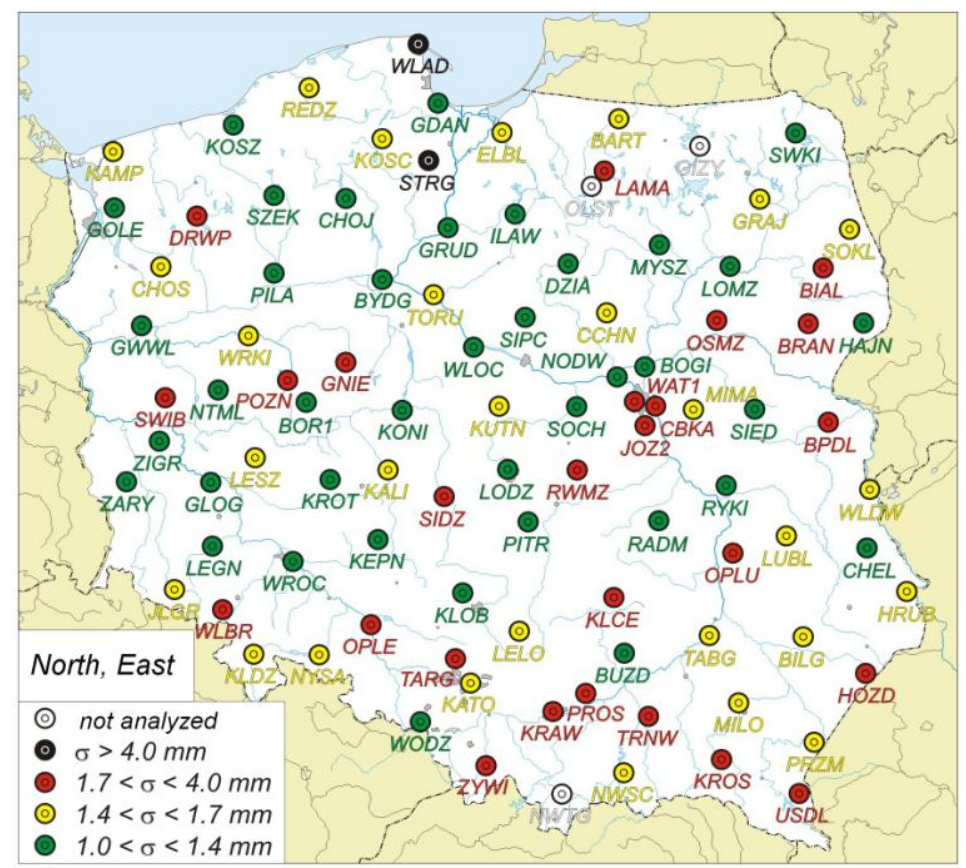

Fig. 2. Stations divided into classes basing on $\sigma_{\text {N-E }}$ (daily solutions)
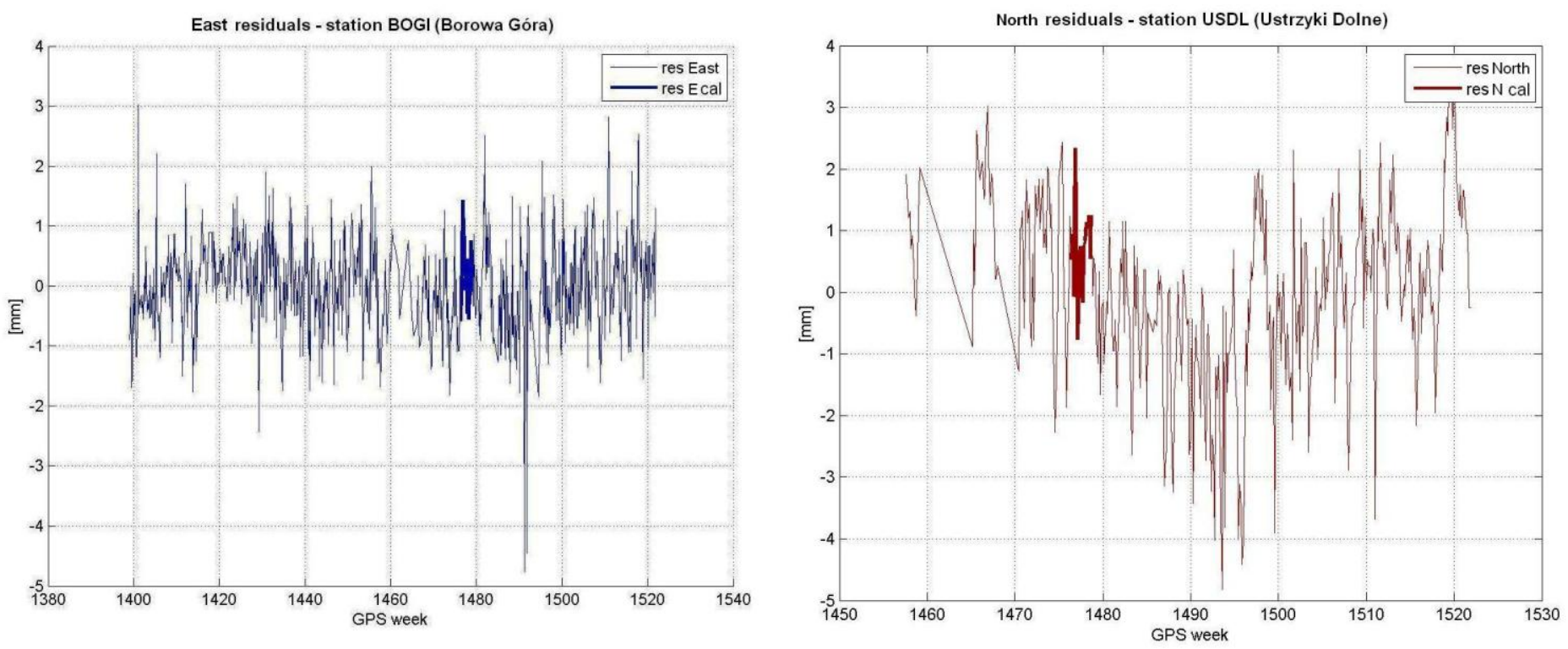

Fig. 3, 4. Horizontal residuals - station BOGI (class I) and USDL (class III) 


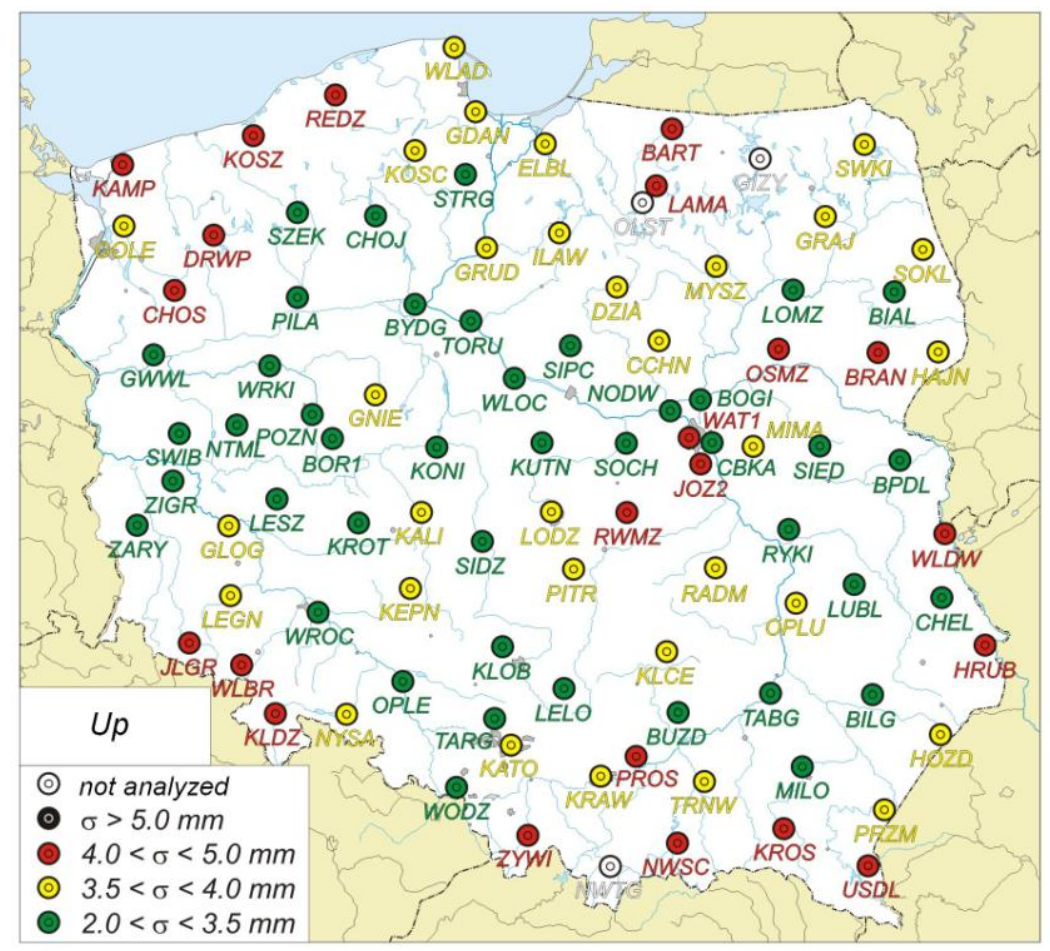

Fig. 5. Stations divided into classes basing on $\sigma_{U p}$ (daily solutions)
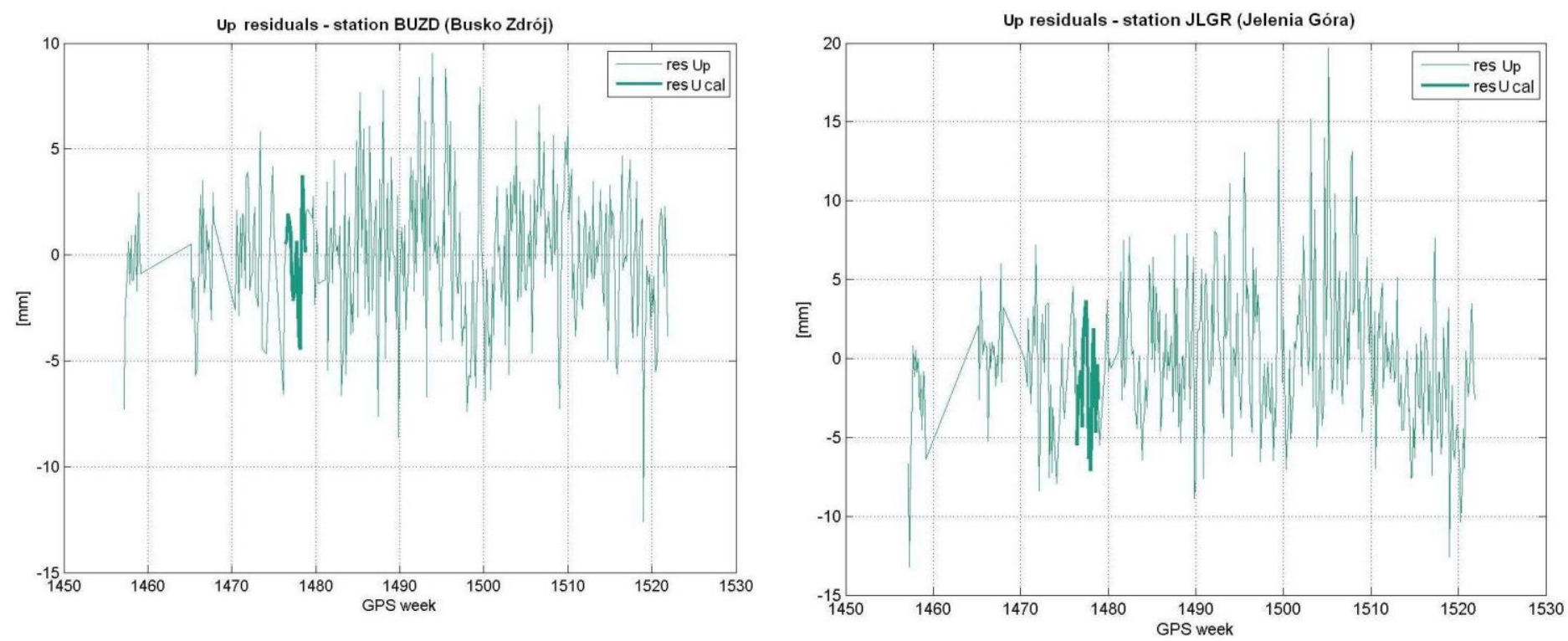

Fig. 6, 7. Vertical residuals - station BUZD (class I) and JLGR (class III)

Bold lines in above figures correspond to ASG-EUPOS calibration period. In some cases, solutions from these days are not typical for cumulative solution from longer period.

\section{COMPARISON WITH EPN}

Weekly solutions obtained in ASG-EUPOS processing were compared with EPN solutions by common station (Fig. 8) coordinates differences determination. Comparison was made for ETRF2000 at epoch of 2000 (Fig. 9, 10) and 2005 (Fig. 12). EPN solutions were taken from EPN_ETRF2000_C1520 and EPN_A_ETRF2000_C1520 (GPS WEEKS 860-1520). The official EPN station coordinates are expressed using geocentric coordinates $\mathrm{X}, \mathrm{Y}, \mathrm{Z}$, so the comparison was done for ortocartesian coordinates instead of North, East, Up components. Due to high differences (Fig. 10) between stations with short observation history (ETRF2000, epoch 2000), comparison between solutions obtained in ASG-EUPOS processing (ETRF2000, epoch 2000) and EPN solutions at the epoch of Minimum Variance 
(Consultations with Ph.D. Ambrus Kenyeres during EUREF Symposium, 27 $7^{\text {th }}-30^{\text {th }}$ May, 2009, Florence, Italy) was made (file EPN_B_ETRF2000_C1525). Results from this comparison significantly improved (Fig. 11).

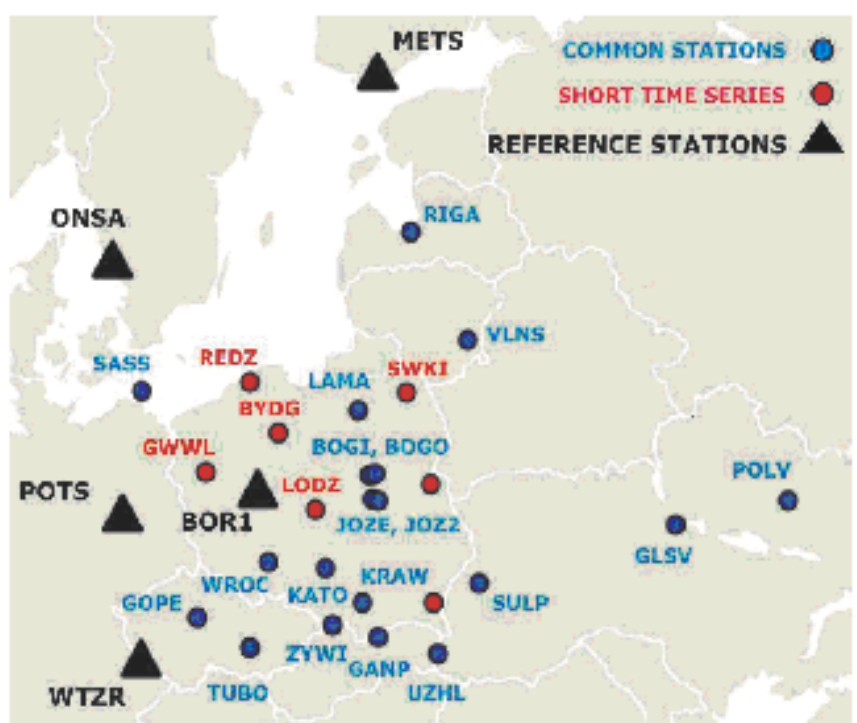

Fig. 8. EPN sites involved in ASG-EUPOS processing

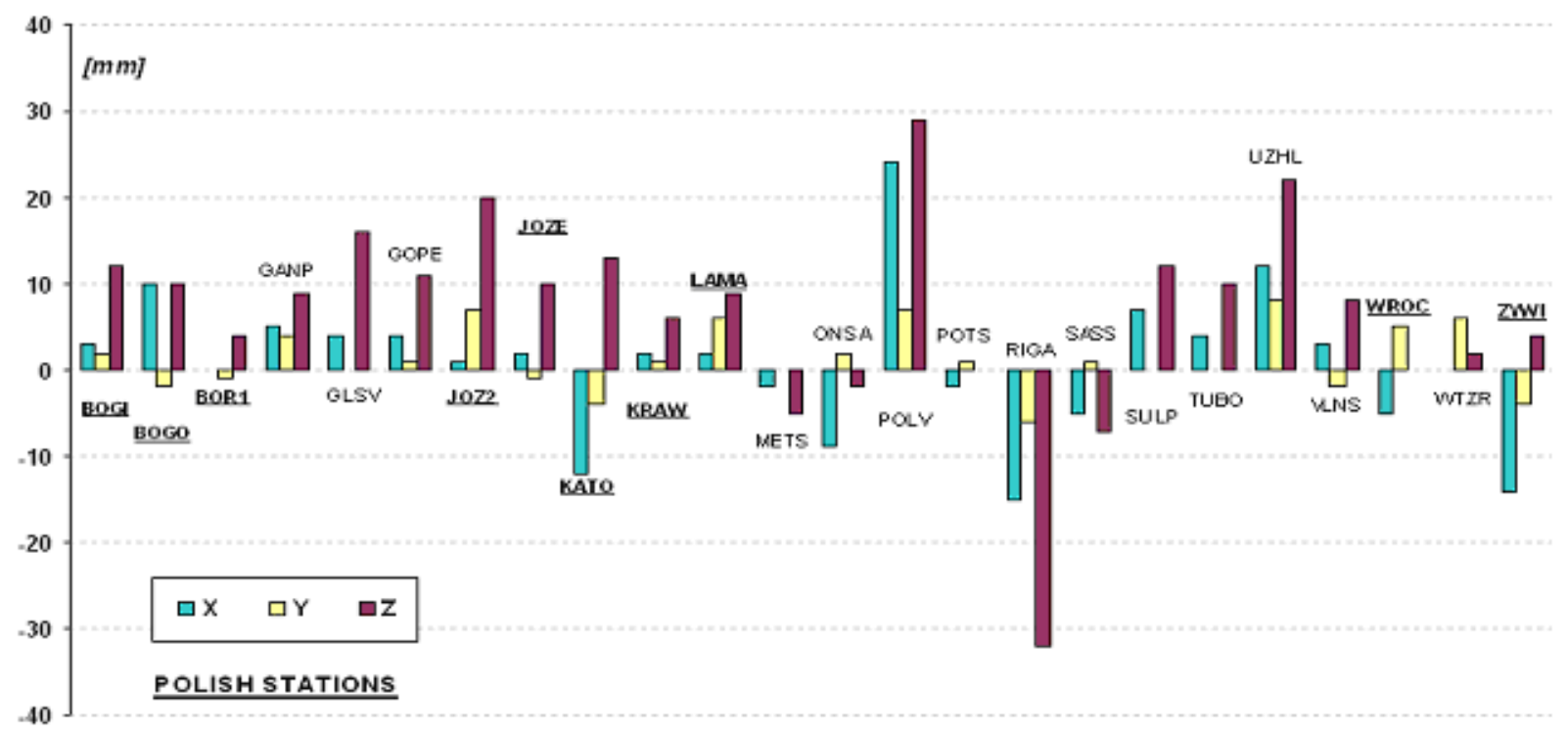

Fig. 9. Comparison of common sites coordinates for ETRF2000 (epoch 2000). 


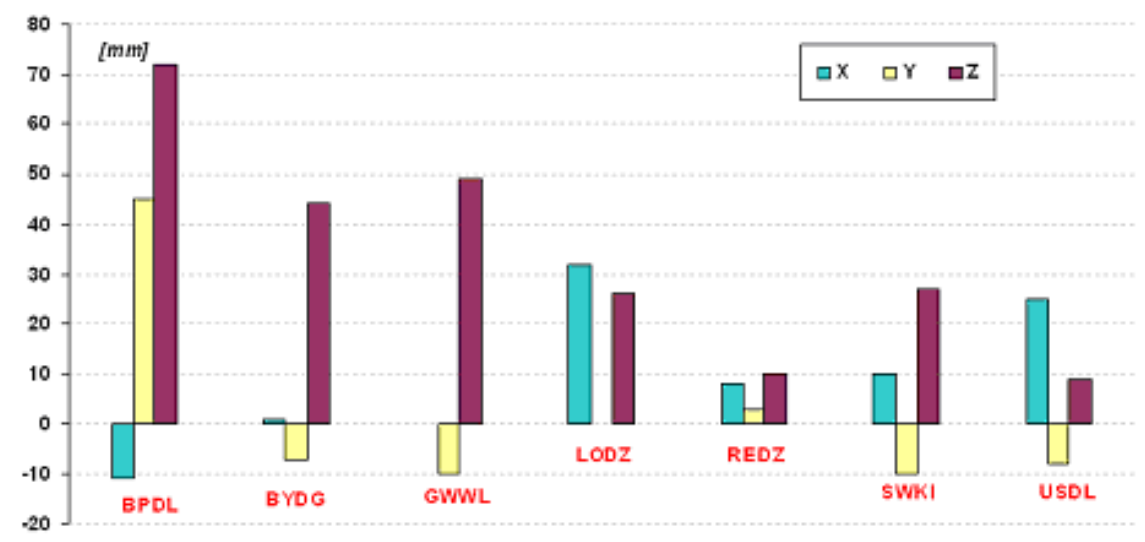

Fig. 10. Comparison of common sites coordinates for ETRF2000 (epoch 2000) - stations which have short observation history

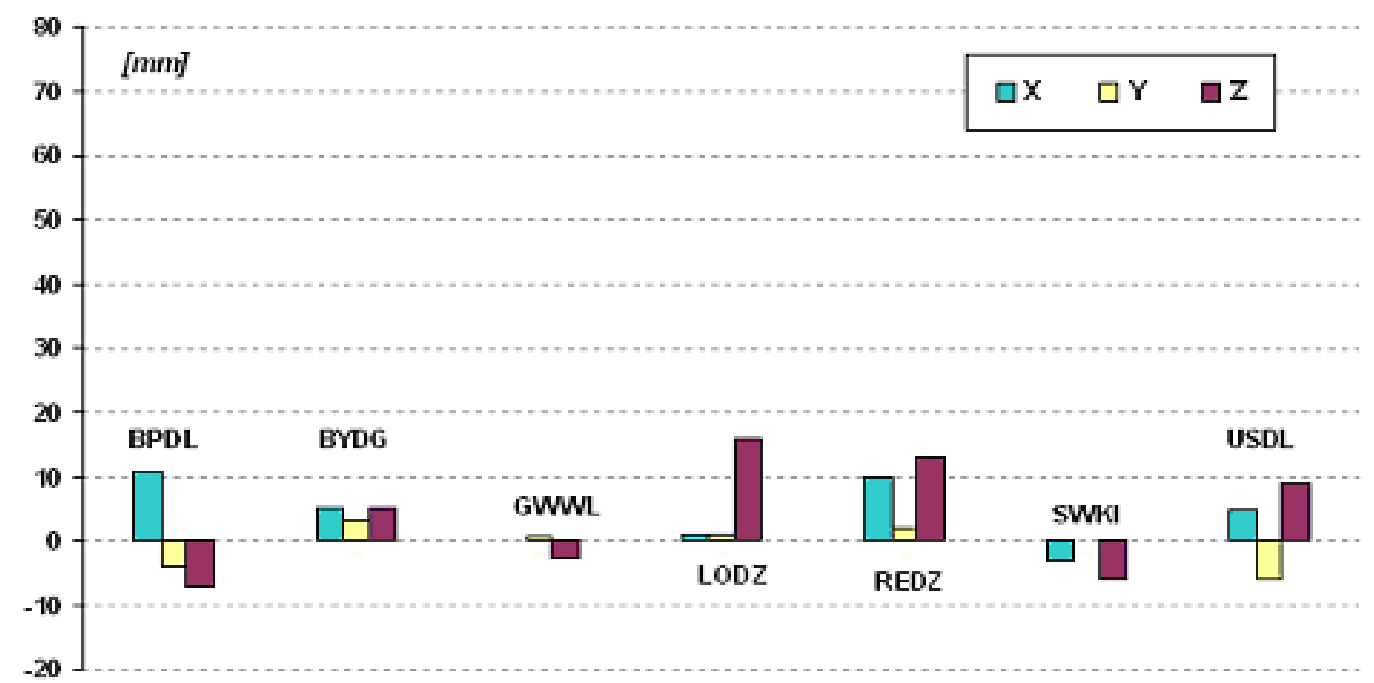

Fig. 11. Comparison of common sites coordinates for ETRF2000 (epoch of Minimal Variance) - stations with short observation history

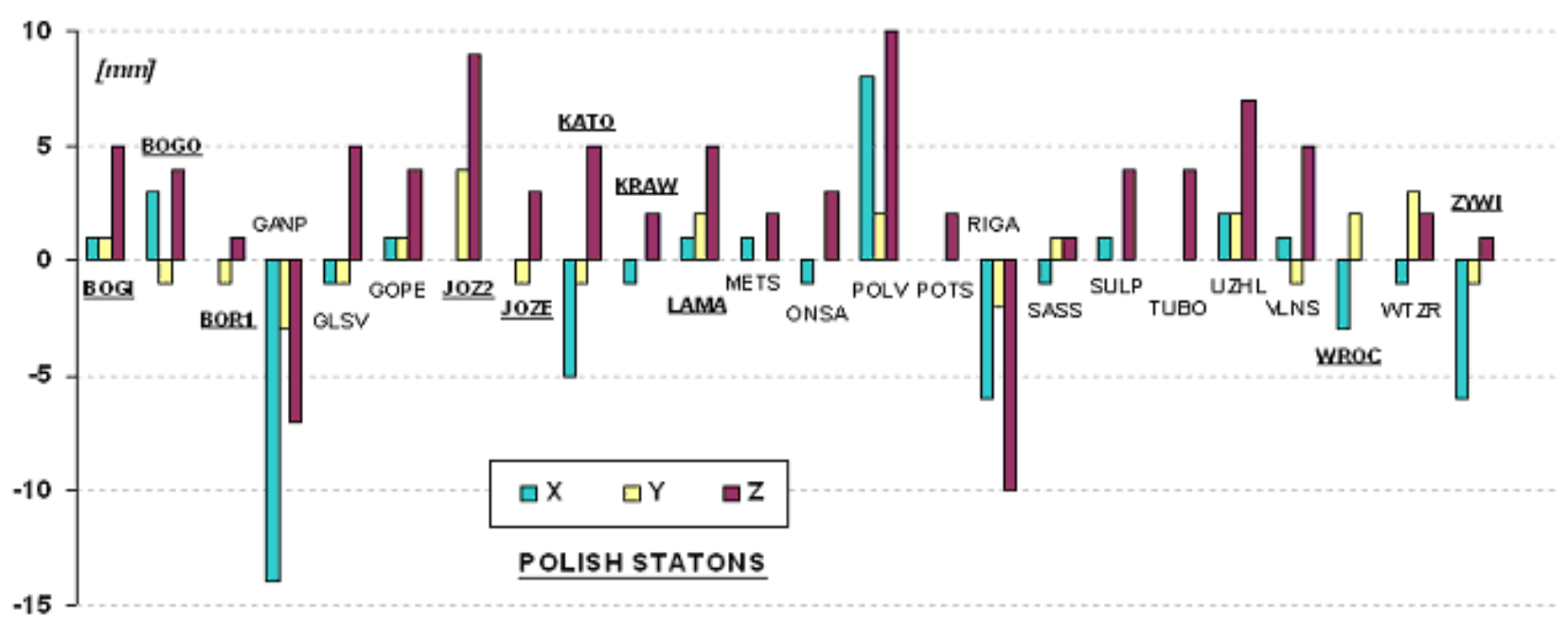

Fig. 12. Comparison of common sites coordinates for ETRF2000 (epoch 2005) 


\section{REFERENCE TO EPN}

CAG also made preliminary researches to combine national and regional networks. Tests were done for 1513-1526 GPS WEEKS using a few different schemes:

1) Joining ASG-EUPOS and EPN combined coordinates with MUT ASG-EUPOS Monitoring Combination (in ITRF2005);

2) Joining ASG-EUPOS and EPN combined coordinates with EPN weekly solutions from LAC combinations (in ITRF2005);

3) Joining ASG-EUPOS and EPN combined coordinates with MUT ASG-EUPOS Monitoring Combination (in ETRF2000R05);

For every type of above mentioned procedures (for all analyzed GPS WEEKS) three parameters of Helmert transformation were determined (components of translation). Representative values for GPS WEEK 1513 are:

\begin{tabular}{|c|c|c|c|}
\hline & Transl N [mm] & Transl E [mm] & Transl Up [mm] \\
\hline 1 & 0,4 & 0,1 & $-2,3$ \\
\hline 2 & $-0,4$ & 0,0 & 4,3 \\
\hline 3 & 0,5 & 0,1 & $-2,3$ \\
\hline
\end{tabular}

Low values of Helmert transformation parameters shows that combination tests gave good results. It is important to compare solutions transformed from ITRF to ETRS using the same procedure - i.e. 7 th version of (Altamimi et al., 2008).

\section{CONCLUSIONS}

Daily ASG-EUPOS solutions allow to analyze different factors (i.e. geophysical) causing disturbances on stations and estimate proper stations' activity. Described procedures were done for short period of data, more reliable and stable results will be achieved after gathering more observations.

Weekly solutions from national GNSS GBAS system are used to ETRS realization and to determine local velocities. They are contribution to European velocity field densifications and they will enable taking into consideration local Earth's crust movements. Currently, kinematic ETRF model is based on data from EPN stations.

Basing on obtained solutions very precise and reliable coordinates of Polish sites can be determined ('cumulative solution'). High accuracy is very important, because ASG-EUPOS soon will fulfill a role of the main national geodetic frame and will enable conservation of ETRF (European Terrestrial Reference Frame) in Poland. Daily and weekly solutions will help to monitor and control whole system activity.

Comparison made between solutions obtained in national processing and official EPN solutions gave good results (differences do not exceed $1 \mathrm{~cm}$ ), so it shows that procedures were done correctly.

\section{REFERENCES}

Altamimi Z., Sillard P., Boucher C. (1994) CATREF software: Combination and analysis of terrestrial reference frames

Altamimi Z. (2004) Towards a Dense European Velocity Field. EUREF Symposium Toledo 2003 Proceedings Vol. 13, (http://www.euref-iag.net/symposia/symposia_2003_Toledo.html)

Altamimi Z., Boucher C. (2008) Memo: Specifications for reference frame fixing in the analysis of a EUREF GPS campaign (http://etrs89.ensg.ign.fr/memo-V7.pdf) 
Beutler G., Bock H., Brockmann E., Dach R., Fridez P., Gurtner W., Habrich H., Hugentobler U., Ineichen D., Jaeggi A., Meindl M., Mervart L., Rothacher M., Schaer S., Schmid R.,

Figurski M. (2007): System monitorowania sieci polskich stacji referencyjnych GPS, Magazyn geoinformacyjny Geodeta, nr 6, 7, 8 (145, 146, 147)

Springer T., Steigenberger P., Svehla D., Thaller D., Urschl C., Weber R. (2006): Bernese GPS software version 5.0

Kenyeres.A, Figurski M., Legrand J., Bruyninx C., Kaminski P., Habrich H. Homogeneous Reprocessing of the EUREF Permanent Network: First Experiences and Comparisons, Bulletin of Geodesy and Geomatics, in press. (EUREF Symposium 2008 in Brussels Proceedings)

Kenyeres A. (2009) Maintenance of the EPN ETRS89 coordinates, presented at the EUREF TWG 2009 Spring Meeting, Feb. 26-27, 2009, Budapest

(http://www.euref.eu/TWG/EUREF\%20TWG\%20minutes/49-Budapest2009/03-e-

ETRSmaint_TWGrepBP.pdf)

Received: 2009-09-22,

Reviewed: 2009-12-14, by J. Bosy,

Accepted: 2009-12-23 